\title{
LOGÍSTICA REVERSA: UMA PROPOSTA PARA MICROEMPRESAS DE CONFECÇÕES LOCALIZADAS NO BAIRRO ALTO PARANÁ NO MUNICÍPIO DE REDENÇÃO-PA
}

\section{REVERSE LOGISTICS: A PROPOSAL FOR CONFECTION MICRO ENTERPRISES LOCATED IN DISTRICT PARANÁ IN REDENÇÃO-PA}

\author{
Waleriana Cavalcante Leão* E-mail: walerianacavalcante2020@hotmail.com \\ Mariele Ferreira Gonçalves* E-mail: marielegoncalves22@gmail.com \\ Janaína Mariana Costa Poletto** E-mail: jcostapoletto100@gmail.com \\ *Universidade do Estado do Pará (UEPA), Redenção, PA \\ **Instituto Tocantinense Presidente Antônio Carlos Porto (ITPAC Porto), Araguaína, TO
}

Resumo: A destinação dos resíduos sólidos se tornou um dos principais problemas ambientais da atualidade. Por isso, as empresas buscam constantemente maneiras de tornar seus processos produtivos sustentáveis, no setor de confecções essa realidade é cada vez mais visível, já que os desperdícios e impactos vão desde a matéria prima até o descarte final, o qual na maioria das vezes é praticado de maneira inadequada. Sendo assim, a elaboração e implementação de um projeto de gerenciamento desses resíduos podem gerar o aumento da competitividade e economia, benefícios sociais e ambientais, levando as organizações a possuírem um fator de diferenciação e competitividade no mercado. Diante desses aspectos, este trabalho tem o objetivo de elaborar alternativas de destinação correta de resíduos sólidos para as microempresas de confecções do bairro alto Paraná no município de Redenção-PA.

Palavras-chave: Logística reversa. Resíduos sólidos. Confecção de vestuário. Meio Ambiente. Economia.

Abstract: The destination of solid waste has become one of the main environmental problems today. For this reason, companies are constantly looking for ways to make their production processes sustainable, in the clothing sector this reality is increasingly visible, since waste and impacts range from raw material to final disposal, which is most often improperly practiced. Therefore, the elaboration and implementation of a project for the management of these residues can generate increased competitiveness and economy, social and environmental benefits, leading organizations to have a differentiating and competitive factor in the market. In view of these aspects, this work aims to develop alternatives for the correct disposal of solid waste for the micro clothing companies in the upper Paraná district in the municipality of Redenção - PA.

Keywords: Reverse logistic. Solid waste. Making of clothing. Environment. Economy.

\section{INTRODUÇÃO}

Atualmente, o Brasil possui o quarto maior parque produtivo de confecção do mundo, com um faturamento que chegou a US $\$ 51,58$ bilhões no ano de 2017 , representando $16,7 \%$ dos empregos gerados no país (TEX BRASIL, 2019). 
Com o consumismo crescente da sociedade atual, o ciclo de vida dos produtos de vestuário se torna curto, e criar produtos de maneira sustentável tem sido um desafio para essas indústrias. No decorrer das etapas de produção são gerados resíduos sólidos, que sem controle ou mitigação, geram impactos ambientais significativos (MILAN et al., 2010; FIEMG, 2015).

Nos últimos anos, os resíduos gerados são maiores que a capacidade de absorção da natureza, sendo que, a sua disposição inadequada em lixões, margens de estradas, terrenos baldios, rios e mares, além de afetar na qualidade do meio ambiente e na vida da população, acarreta problemas relacionados à poluição do ar, do solo e das águas, bem como riscos à saúde pública (MESACASA, 2012).

Diante disso, existe a chamada logística reversa que objetiva um processo de planejamento, implementação e controle eficiente de matérias-primas, materiais em processo, produtos acabados e informações que vão desde o ponto de consumo até o ponto de origem, com finalidade de atender as necessidades de recuperação de valor e de um descarte correto (LEITE, 2002).

Sendo assim, este trabalho tem como objetivo apresentar alternativas de destinação correta e reaproveitamento de resíduos sólidos para as microempresas de confecções do bairro alto Paraná no município de Redenção-PA.

\section{LOGÍSTICA}

Segundo Ballou (2009) a logística pode ser definida como a combinação de quatro atividades básicas: aquisição, movimentação, armazenagem e a entrega de produtos. Essas atividades só funcionam se houver um planejamento logístico, bem como a interação correta desses processos. Sendo assim, a logística se torna o conjunto de tarefas necessárias para que o produto chegue ao cliente com qualidade e rapidez.

Santana e Neto (2015) complementam que, de modo geral, esta é conhecida como uma atividade de distribuição física, fornecimento ou gerência de mercadorias e transporte. Apesar disso, até pouco tempo, a logística era vista em uma posição de auxiliadora nas empresas, sendo responsável somente pela transmissão de 
produtos ou pela contratação das transportadoras, porém, atualmente, sabe-se que ela vai muito além do que se imaginava.

Portanto, a logística tem como objetivo disponibilizar os produtos e serviços no lugar certo e momento exato, de modo que os clientes os recebam com qualidade e com um custo adequado. No entanto, é necessário a conexão de informações, condução, acervo, armazenamento, manejo de materiais e embalagem. Por isso, as organizações precisam estar cada vez mais voltadas para seus clientes, procurando subsídios, conhecimento, produtos e serviços modernos, investindo em tecnologia e processos bem-sucedidos (SANTANA; NETO, 2015).

Dentro desses aspectos, a logística se divide em quatro campos de atuação, sendo eles: a logística de suprimentos, a logística de produção, a logística de distribuição e a logística reversa.

A logística de suprimentos atua no campo das relações entre as empresas e seus fornecedores, tendo o objetivo de desenvolver produtos, garantindo a qualidade das matérias-primas, componentes e embalagens, fazendo com que as exigências de produção sejam atendidas com menor custo total. Além disso, a logística de produção aborda os processos de transformação para obtenção do produto final ou acabado, dentro dos prazos estabelecidos. A logística de distribuição trata da distribuição física dos produtos acabados, para o alcance de um nível adequado de serviço e atendimento ao cliente (CHING, 2010).

Segundo Carvalho e Miguez (2011) a logística reversa, também conhecida como logística verde, envolve o caminho inverso da logística regular, ou seja, o produto parte do consumidor e realiza o percurso de volta para seu centro de produção, podendo ser novamente reaproveitado de forma parcial ou complementar, bem como descartado de maneira ambientalmente correta. Corroborando com a ideia, Marchi (2011) afirma que a logística facilita a coleta e a devolução dos resíduos sólidos, para tratamento ou reaproveitamento, visando novas alternativas de retorno dos resíduos, estendendo a vida útil das matérias-primas utilizadas e buscando a não geração de rejeitos.

Nesse contexto, a logística se mostra de suma importância para as organizações, sendo que, a mesma promove maior nível de rentabilidade nos serviços de distribuição aos clientes, por meio do planejamento, organização e 
controle das atividades, e armazenagem que visam melhorar o fluxo dos produtos (BALLOU, 2006).

\subsection{Logística Reversa}

A logística reversa é definida pelo Council of Logistics Management (2004) como o processo de planejamento, implementação e controle eficiente e eficaz do fluxo de matérias-primas, produtos em processamento, produtos acabados e informações relacionadas do ponto de consumo até o ponto de origem, com 0 propósito de recapturar o fluxo, criar valor ou realizar o descarte adequadamente.

A logística verde, abrange o gerenciamento e descarte dos resíduos sólidos, a partir do refluxo enviado do consumidor até o início da cadeia de suprimentos. Por décadas, essa atividade foi vista com preconceito e descrédito pelas empresas, pois se pensava ter função puramente ambiental, ou seja, sem retorno financeiro (SILVA, et al., 2018). Contudo, atualmente entende-se que existe o potencial de se agregar valores de diversas naturezas como: econômico, ecológico, legal, logístico e de imagem corporativa (MARQUEZIM, et al., 2011).

Apesar de representar uma pequena parcela do montante movimentado na logística direta, a logística reversa tem adquirido importância, pois, além de gerar retorno econômico, contribui para a sustentabilidade do planeta, sobretudo quando se analisa que após o processo logístico direto são gerados diversos resíduos, tanto de bens no final de sua vida útil, como também de bens sem ou com pouco uso (GUARNIERI, 2014).

Essa atividade tem recebido nos últimos anos uma atenção importante, por parte de pesquisadores e setores produtivos, em virtude de uma crescente demanda dos consumidores por empresas com responsabilidade socioambiental, e um aumento nos custos de matérias-primas (HALL, et al. 2013). Para Guimarães e Salomon (2015), a logística reversa contribui estrategicamente e operacionalmente, com a recuperação de valor econômico, adicionando valor na prestação de serviço, na adequação as leis, na mitigação de riscos e na melhoria da imagem da empresa. 


\section{MEIO AMBIENTE}

Quando falamos em meio ambiente, vem à tona uma definição muito ampla acerca do tema que diz respeito a vários elementos presentes na vida em geral, seja de maneira cultural, artificial, ecológica, tudo que temos gira em torno do meio ambiente, sendo um direito de toda a coletividade o uso comum, como também, a sua preservação, como está imposto na Constituição da República Federativa do Brasil de 1988:

Art. 225. Todos têm direito ao meio ambiente ecologicamente equilibrado, bem de uso comum do povo e essencial à sadia qualidade de vida, impondo-se ao poder público e à coletividade o dever de defendê-lo e preservá-lo para as presentes e futuras gerações (BRASIL, 1998).

E tratando deste assunto, podemos perceber diariamente as grandes alterações que o meio ambiente vem sofrendo destruições causadas pela humanidade, por isso, foram instituídas legislações pertinentes que tratam da proteção de uma parte fundamental do planeta.

As grandes empresas, em sua maioria, são responsáveis por tais destruições, como por exemplo, a indústria têxtil que apesar de ser uma grande geradora de empregos, está há mais de 200 anos no país, possuindo o quarto maior parque produtivo de confecção do mundo, é uma das maiores geradoras de resíduos nocivos ao meio ambiente.

Nesse interim, foi necessário criar uma legislação para instituir regras de cuidado e responsabilização, no que diz respeito as empresas de direito público e privado, sendo assim, criada a lei 12. 305 de 02 de agosto de 2010, que dispõe:

Art. $1^{\circ}$ Esta Lei institui a Política Nacional de Resíduos Sólidos, dispondo sobre seus princípios, objetivos e instrumentos, bem como sobre as diretrizes relativas à gestão integrada e ao gerenciamento de resíduos sólidos, incluídos os perigosos, às responsabilidades dos geradores e do poder público e aos instrumentos econômicos aplicáveis (Brasil, 2010).

$\S 1^{\circ}$ Estão sujeitas à observância desta Lei as pessoas físicas ou jurídicas, de direito público ou privado, responsáveis, direta ou indiretamente, pela geração de resíduos sólidos e as que desenvolvam ações relacionadas à gestão integrada ou ao gerenciamento de resíduos sólidos (Brasil, 2010). 
Cabe ressaltar a instituição da lei 9.605 de 12 de fevereiro de 1998, que foi um grande marco nas questões relativas ao meio ambiente, a qual dispõe a cerca das sanções penais e administrativas a respeito das atividades lesivas ao meio ambiente, e que dispõe:

Art. 2ำ Quem, de qualquer forma, concorre para a prática dos crimes previstos nesta Lei, incide nas penas a estes cominadas, na medida da sua culpabilidade, bem como o diretor, o administrador, o membro de conselho e de órgão técnico, o auditor, o gerente, o preposto ou mandatário de pessoa jurídica, que, sabendo da conduta criminosa de outrem, deixar de impedir a sua prática, quando podia agir para evitá-la (Brasil, 1998).

Art. 3ำ As pessoas jurídicas serão responsabilizadas administrativa, civil e penalmente conforme o disposto nesta Lei, nos casos em que a infração seja cometida por decisão de seu representante legal ou contratual, ou de seu órgão colegiado, no interesse ou benefício da sua entidade (Brasil, 1998).

Podendo ser aplicada, também, no que se trata sobre os resíduos sólidos, as legislações do Sisnama, SNVS, Suasa e Sinmetro:

\begin{abstract}
Art. $2^{\circ}$ Aplicam-se aos resíduos sólidos, além do disposto nesta Lei, nas Leis nos 11.445, de 5 de janeiro de 2007, 9.974, de 6 de junho de 2000, e 9.966, de 28 de abril de 2000, as normas estabelecidas pelos órgãos do Sistema Nacional do Meio Ambiente (Sisnama), do Sistema Nacional de Vigilância Sanitária (SNVS), do Sistema Unificado de Atenção à Sanidade Agropecuária (Suasa) e do Sistema Nacional de Metrologia, Normalização e Qualidade Industrial (Sinmetro).
\end{abstract}

Diante disso, a preservação do meio ambiente ainda é um tabu que não pode ser tratado de maneira simplista, cabendo às indústrias têxteis a responsabilidade pelos resíduos sólidos, pela conservação, e buscando a sustentabilidade do meio ambiente. Sendo assim, as leis que tratam dos resíduos sólidos e dos crimes ambientais, são grandes conquistas para preservar o meio ambiente, como também, tratada com fulcro na Constituição Federal de 1988, a responsabilidade social com o meio ambiente.

Portanto, buscando uma maior conscientização de toda a população e das indústrias, sendo impostas para tal, com o advento da lei 12.305 de 02 de agosto de 2010, que impõe diretrizes de aplicações de toda a logística de coleta e destinação para os produtos pós-consumo, como a reciclagem e o descarte. 


\title{
4 RESÍDUOS SÓLIDOS GERADOS NA INDÚSTRIA DE CONFECÇÕES
}

Os resíduos sólidos, em sua grande maioria, são gerados das confecções, isso por que existe um consumo constante desses produtos provenientes das suas renovações a cada estação do ano, e de suas sazonalidades (BARBOSA, 2015).

A composição do ciclo de produção de uma peça de vestuário se resume nas seguintes etapas: etapa de elaboração do encaixe dos moldes das partes componentes, enfesto (disposição do tecido em camadas sobrepostas), corte do tecido, costura, arremate, revisão, etiquetagem, dobra e embalagem. Sendo assim, os resíduos sólidos são os mais produzidos pela indústria de confecção, que na maioria não são considerados nocivos (AMARAL, et al., 2014).

Os resíduos sólidos, segundo o inciso XVI do artigo $3^{\circ}$ da Política Nacional de Resíduos Sólidos, são definidos como:

\begin{abstract}
Material, substância, objeto ou bem descartado resultante de atividades humanas em sociedade, cuja destinação final se procede, se propõe proceder ou se está obrigado a proceder, nos estados sólido ou semissólido, bem como gases contidos em recipientes e líquidos cujas particularidades tornem inviável o seu lançamento na rede pública de esgotos ou em corpos d'água, ou exijam para isso soluções técnica ou economicamente inviável em face da melhor tecnologia disponível. (BRASIL, 2010).
\end{abstract}

Conforme a NBR 10.004/2004, os resíduos de confecções seguem a seguinte classificação: classe II A, não perigosos e não inertes, que possuem propriedades como biodegradabilidade, combustibilidade ou solubilidade em água. E, quando esses materiais entram em contato com algo contaminado, passam a ser classificados como resíduos de classe I, perigosos, apresentando riscos à saúde pública e ao meio ambiente (ABNT, 2004).

Os desperdícios de matéria-prima gerados pela indústria de confecções são considerados significativos, esses resíduos, em sua maioria, são dos tecidos utilizados no processo de corte que segue as caraterísticas do molde de cada peça, onde a folha do tecido que entra processo de produção tem um padrão retangular, sendo que para iniciar o corte deve-se encaixar o molde de maneira que não haja desperdícios abundantes com esses componentes, já que os eles seguem formas variadas (BARBOSA, 2015). 
Apesar de um bom planejamento, da qualidade da matéria prima, de capacitação a mão de obra e utilização de tecnologias, visando reduzir as perdas na produção, sempre haverá perdas de tecido, os quais não poderão ser evitados (PINHEIRO, 2014).

Além dos retalhos de tecidos, existem outros resíduos sólidos provenientes das confecções, como por exemplo, os papeis utilizados nos encaixes dos moldes, fitas, bobinas e cones plásticos, zíperes, botões, linhas, agulhas e alfinetes, plásticos e papelão (MENEGUCl et al., 2015).

Segundo Lopes (2013), existem 54 tipos de resíduos provenientes das confecções de vestuários, sendo que alguns são específicos do setor, como:

- retalhos - gerados, principalmente, na fase de corte, pela falta de eficiência na moldagem da peça, que pode atingir $30 \%$ do tecido ou malha;

- pó de overlock - resultantes da costura das máquinas refiladoras, provenientes do excesso de tecido gerado pela etapa de corte;

- carretéis plásticos - gerados de linhas e elásticos das etapas de costura e bordados;

- tubos de papelão e de PVC - provenientes dos tecidos e papel usados nos moldes;

- outros resíduos - agulhas, linhas de acabamento e arremates, lâmpadas, embalagens de óleo lubrificante, tecidos ou estopas sujas, usados na limpeza e manutenção das máquinas.

\section{METODOLOGIA}

Esse trabalho tem como objetivo elaborar alternativas de destinação correta de resíduos sólidos para as microempresas de confecções do bairro alto paraná no município de Redenção - PA. Para isso, a pesquisa se deu por meio de uma abordagem qualitativa, que Fleury et al. (2018) afirma ser a análise da particularidade de cada indivíduo envolvido na pesquisa, contribuindo para o desenvolvimento do estudo em questão. 
A técnica utilizada foi o estudo exploratório, pois, pretende-se elaborar opções que podem ser implantadas na cidade para o reaproveitamento dos resíduos sólidos das confecções. Conforme Gil (2017), esse procedimento tem como objetivo construir hipóteses através de um melhor contato com o problema, com intuito de torná-lo mais explícito.

Para realização da pesquisa, o procedimento técnico escolhido foi o estudo de caso, pois esse se caracteriza por "uma pesquisa empírica, baseada em evidências qualitativas e quantitativas, que investigam um fenômeno contemporâneo inserido no contexto da vida real" (GANGA, 2012, p. 260), sendo essa, a forma de estudo que mais se adequa aos objetivos desse trabalho.

Esse estudo foi conduzido a partir de 4 etapas:

Etapa 1 - levantamento bibliográfico: levantamento bibliográfico acerca dos assuntos abordados durante o trabalho, para gerar maior familiaridade com o tema.

Etapa 2 - visita à empresa: foram conduzidas visitas as empresas estudadas para a coleta dos dados necessários a continuação da pesquisa.

Etapa 3 - coleta de dados: ao conduzir visitas as empresas estudadas, foram aplicados questionários com perguntas fechadas, sobre a destinação dos resíduos sólidos produzidos nas mesmas.

Etapa 4 - tratamento dos dados: a partir das respostas obtidas, pode-se elaborar alternativas para o descarte adequado dos resíduos sólidos resultantes do processo produtivo das microconfecções.

\section{RESULTADOS E DISCUSSÕES}

Levando em consideração o conhecimento dos gestores das microempresas, quanto à destinação final dos resíduos sólidos, como pode ser apresentado na figura 01: 
Figura 1 - Destinação final dos resíduos sólidos.

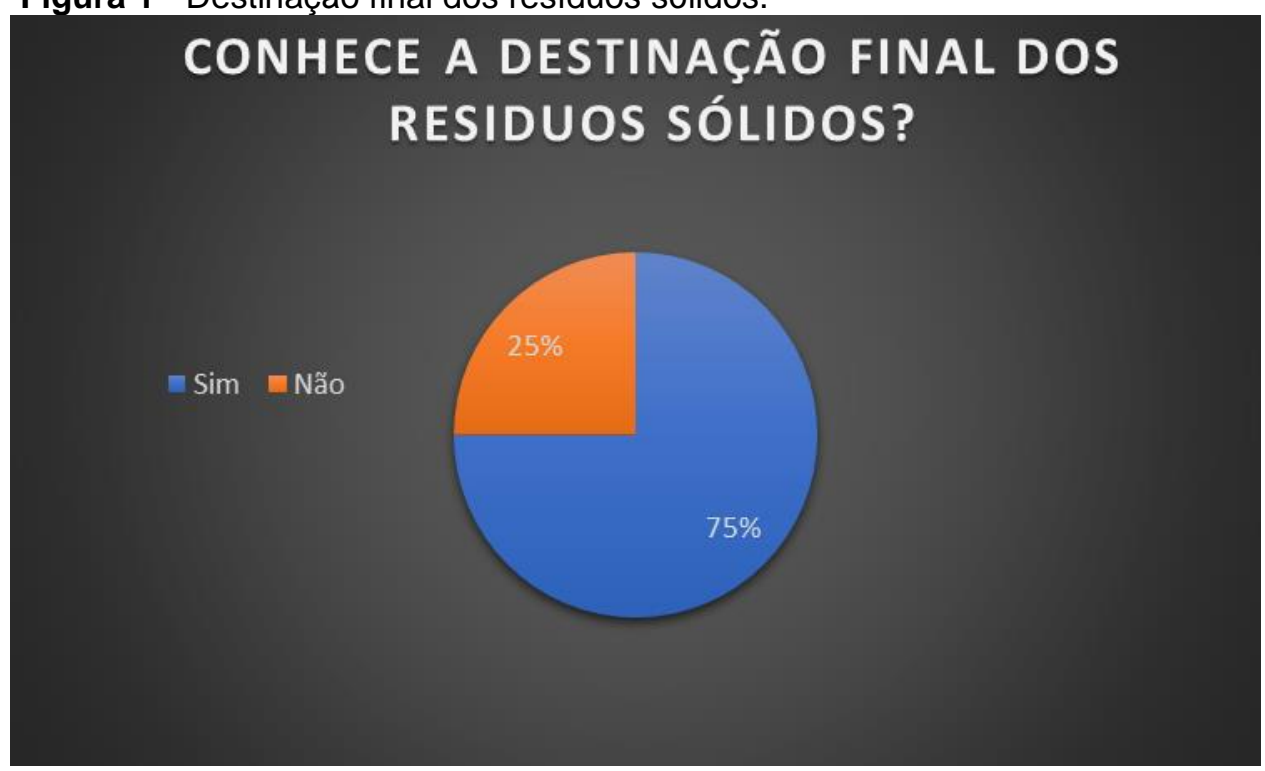

Fonte: Autores (2019).

Dentre as empresas que contribuíram para essa pesquisa, uma não possui o conhecimento de descarte adequado para os resíduos gerados na sua produção, e três possuem conhecimento de destinação correta para os seus resíduos.

Quanto à destinação correta dos resíduos sólidos realizados por essas organizações, as Quatro empresas descartam no lixo comum todos os tipos de resíduos gerados na produção, desde aqueles utilizados na modelagem da peça até os usados na manutenção, impossibilitando o reaproveitamento dos mesmos, já que quando misturados a algum material contaminado, passam a ser nocivos ao homem e ao meio ambiente.

Sobre qual etapa da produção apresenta maior significância na geração de resíduos, o setor de corte foi o mais apontado, nenhuma empresa constatou que existe algum tipo de resíduo na etapa de costura ou outros, no entanto é indispensável frisar que independente do porte da empresa, sempre irá gerar resíduo em todas as etapas. Com isso, é possível afirmar que mesmo em menor quantidade, comparados a etapa apontada pelos gestores, eles ainda irão causar impactos ao meio ambiente, talvez até em maiores proporções.

$\mathrm{Na}$ Figura 02, estão descritas as informações que diz respeito ao comportamento empresarial em relação ao descarte dos resíduos, o que realmente levam essas empresas a não adotarem métodos corretos para a destinação. 
Figura 2 - Motivos de não adoção das práticas corretas de descarte dos resíduos

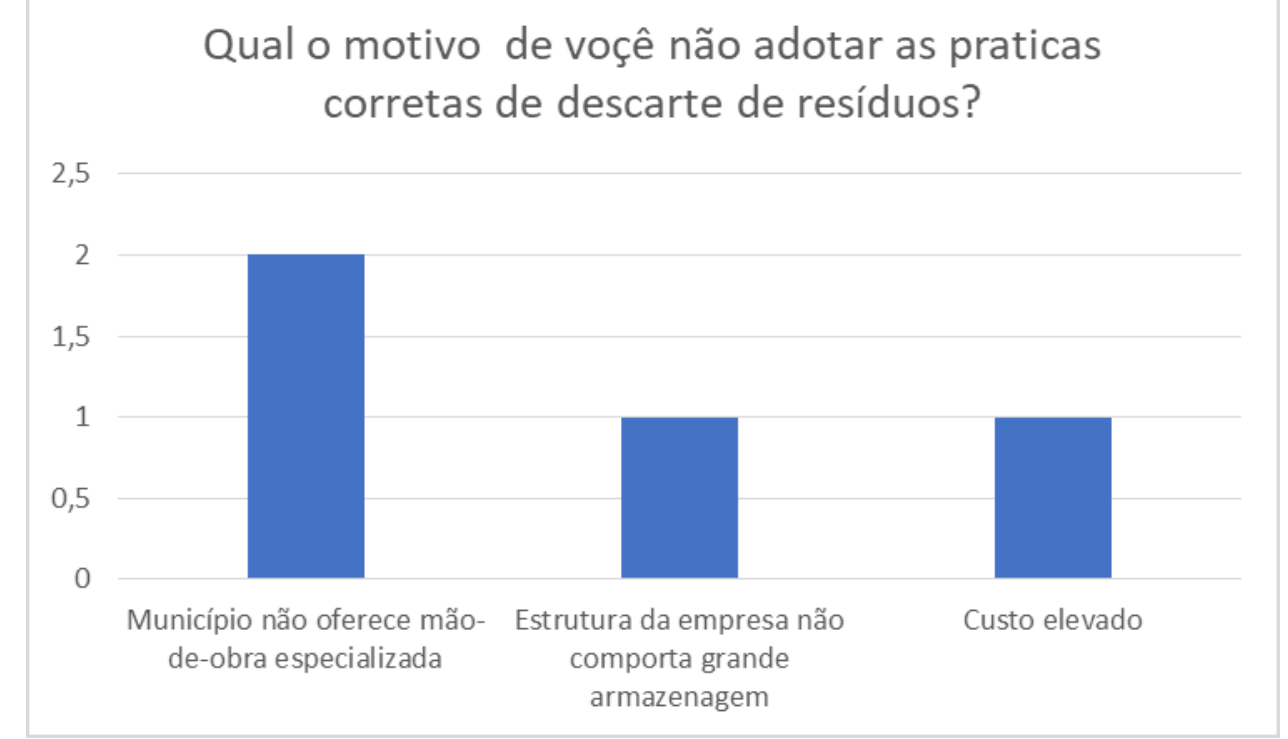

Fonte: Autores (2019).

Das quatro empresas, duas responderam que o município não oferece mão de obra especializada, uma respondeu que a estrutura da empresa não comporta uma grande quantidade de resíduos armazenados, e a outra respondeu que o custo é elevado, já que não existem esses tipos de processos na região.

\subsection{Propostas de Melhorias}

A referente pesquisa demonstrou que, existe no munícipio a falta de práticas da logística reversa, e um considerável desperdício de materiais que poderiam ser reincorporados no processo produtivo ou serem utilizados como matéria-prima de outros produtos.

No quadro abaixo, estão descritos os resíduos sólidos gerados nas confecções de vestuário, e sua possível destinação seguindo medidas para a logística reversa. 
Quadro 1 - propostas de melhorias.

\begin{tabular}{|l|l|}
\hline \multicolumn{1}{|c|}{ Resíduos Sólidos } & \multicolumn{1}{c|}{ Logística Reversa } \\
\hline Retalhos de tecidos & $\begin{array}{l}\text { Reutilizar e: Confecção de peças, artesanatos, brinquedos, } \\
\text { enchimento de almofadas, customizações ou ainda reciclar. }\end{array}$ \\
\hline Fitas e linhas & Coleta seletiva e destinação para reciclagem. \\
\hline Zíperes e Botões & Coleta seletiva e destinação para a reciclagem. \\
\hline $\begin{array}{l}\text { Bobinas e Cones } \\
\text { Plásticos }\end{array}$ & $\begin{array}{l}\text { Quando em bom estado, podem ser utilizados para a confecção } \\
\text { de artesanatos e brinquedos, além de servir para enrolar os fios; } \\
\text { caso contrário, segue para reciclagem. }\end{array}$ \\
\hline Agulhas e Alfinetes & Coleta seletiva e destinação para a reciclagem. \\
\hline $\begin{array}{l}\text { Plásticos, Papeis e } \\
\text { Papelões. }\end{array}$ & Coleta seletiva e destinação para a reciclagem. \\
\hline
\end{tabular}

Fonte: Autores (2019).

O processo de reutilização e reciclagem são maneiras de reaproveitar os resíduos sólidos, em que esses podem ser utilizados sem alteração as suas características, sendo aproveitado em seu estado atual pelo processo chamado de reutilização, e também podendo ser transformado em insumos ou novo produto, alterando suas propriedades físicas, químicas ou biológicas pelo processo de ciclagem (BRASIL, 2010).

Para isso, existe a necessidade da implantação de uma cooperativa de reciclagem de resíduos sólidos gerados nas confecções de vestuários, partindo de um projeto de integração da sociedade e preservação ambiental. Esse projeto, terá o intuito de desenvolver um plano de gestão de resíduos sólidos, disseminando os fundamentos da política Nacional de Resíduos Sólidos (Lei № 12.305 de 02/08/2010), a qual decreta que, a gestão dos resíduos gerados, incluindo os perigosos é de inteira responsabilidade dos geradores e do poder público.

Além de seguir as premissas da responsabilidade socioambiental, o projeto pretende agregar valor para a indústria de confecções de vestuário, visando também a geração de renda de forma justa para cidadãos que precisam garantir a subsistência da sua família.

Com a implantação do projeto, as atividades desenvolvidas pelos trabalhadores serão formalizadas e padronizadas, cujo todo o material coletado das microempresas de confecções será encaminhado para a cooperativa, e os catadores ficaram responsáveis pela tarefa de fazer a separação dos resíduos e dos rejeitos, possibilitando o reaproveitamento e a reciclagem desses materiais, evitando que 
toneladas de matérias-primas sejam descartadas em lugares inapropriados, eliminando os impactos ambientais e sociais.

Para isso, é necessário que as instituições governamentais e não governamentais ofereçam para a população, palestras e cursos que, conscientizem e capacitem os mesmos, a fim de disseminar as práticas de logística reversa.

\section{CONCLUSÃO}

O trabalho apresentado pode ser considerado uma proposta inicial de valorização e destinação dos resíduos gerados pelas microempresas de confecção de vestuário, trazendo a logística reversa como instrumento de suporte, para o desenvolvimento de novos produtos, metodologias, processos e tecnologias de gestão, reciclagem e reutilização.

A inexistência de práticas voltadas para a logística reversa, e o costume das pessoas de não separar resíduos e rejeitos, faz com que o material que poderia ser fonte de renda para a população e gerar economia para o país, passe a ser um problema socioambiental, já que quando não realizado a coleta esses vão para aterros e lixões a céu aberto.

A partir do cumprimento da legislação da política nacional de resíduos sólidos a qual evita ônus para o negócio, inclusive para as microempresas, a idealização e o implemento de um projeto de gerenciamento desses resíduos pode gerar o aumento da competitividade e economia, benefícios sociais e ambientais, o que leva a organização a possuir um fator de diferenciação no mercado.

Diante desses aspectos, é necessária a conscientização da população, através de palestras e cursos para diminuir o consumo de matérias primas-virgens. Além disso, práticas de ações da logística reversa, aumentam o ciclo de vida dos produtos, além de possibilitar o reaproveitamento e a reciclagem desses materiais, evitando que toneladas de matérias primas sejam descartadas em lugares inapropriados, eliminando os impactos ambientais e sociais.

\section{REFERÊNCIAS}

ABNT - ASSOCIAÇÃO BRASILEIRA DE NORMAS TÉCNICAS. NBR 10.004: Resíduos sólidos - Classificação, Rio de Janeiro, 2004. 
AMARAL, M. C.; BARUQUE, R. J.; FERREIRA, A. C. A política nacional de resíduos sólidos e a logística reversa no setor têxtil e de confecção nacional. In: CONGRESSO CIENTÍfICO TÊXTIL E DE MODA, 2., 2014, São Paulo. [Anais...] São Paulo: ABTT, 2014.

BALLOU, R. H. Gerenciamento da cadeia de suprimentos: logística empresarial. 5. ed. Porto Alegre: Bookman, 2006.

BARBOSA, G. D. Alternativas de parcerias para a prática da logística reversa entre indústrias têxteis e de confecções do APL de Cianorte-PR: uma análise espacializada. 2015. Monografia (Especialização em Engenharia de Produção) - Universidade Tecnológica Federal do Paraná. Ponta Grossa, 2015.

BRASIL. Lei no 12.305, de 02 de agosto de 2010. Institui a Política Nacional de Resíduos Sólidos; altera a Lei no 9.605, de 12 de fevereiro de 1998; e dá outras providências. Diário Oficial da República Federativa do Brasil, Brasília, DF, CXLVII, n. 147, 03 ago. 2010. Seção 1, p. 3-7.

CARVALHO, H. \& MIGUEZ, E. Indústria do Samba e Logística Reversa: Estudo de Caso do Carnaval Carioca e a Cidade do Samba. In: CONGRESSO DE ENGENHARIA DO ENTRETENIMENTO, RIO O ANO TODO, 2., 2006. [Anais...]. Rio de Janeiro: E-papers, p. 149-151, 2006.

CAUCHICK-MIGUEL, P. A. et al. Metodologia de pesquisa em engenharia de produção e gestão de operações. 3. ed. Rio de Janeiro: Elsevier, 2018.

CHING, H.Y. Gestão de estoques na cadeia de logística integrada: Supply chain. 4 ed. São Paulo: Atlas, 2010.

COUNCIL OF LOGISTICS MANAGEMENT. Acesso em: 24 out. 2019. Disponível em: http://www.clm1.org

FIEMG - FEDERAÇÃO DAS INDÚSTRIAS DO ESTADO DE MINAS GERAIS. Guia técnico ambiental da indústria têxtil. Belo Horizonte, 2014. Disponível em:

http://www7.fiemg.com.br/Cms Data/Contents/central/Media/Documentos/Biblioteca/PDFs/F IEMG/MeioAmbiente/2014/CartilhasPublica\%C3\%A7\%C3\%B5es/FI-0054-14-CARTILHAPRODUCAO-MAIS-LIMPA-INTRANET.pdf . Acesso em: 15 abril 2015.

GANGA, G. M. D. Trabalho de conclusão de curso na engenharia de produção: um guia prático de conteúdo e forma. São Paulo: Atlas, 2012.

GIL, A. C. Como elaborar projetos de pesquisa. 6. ed. São Paulo: Atlas, 2017.

GUARNIERI, P. Logística reversa: em busca do equilíbrio econômico e ambiental. Editor clube de autores, 2014.

GUIMARÃES, J. L; SALOMON, V. A. P. ANP applied to the evaluation of performance indicators of reverse logistics in footwear industry. Procedia Computer Science, 55, p. 139148, 2015. https://doi.org/10.1016/i.procs.2015.07.021

J. HALL, Dianne, et al. Reverse logistics goals, metrics, and challenges: perspectives from industry. International Journal of Physical Distribution \& Logistics Management, v. 43, n. 9, S. 768-785, 2013. https://doi.org/10.1108/IJPDLM-02-2012-0052 
LEITE, P.R . Logística Reversa: a complexidade do retorno de produtos. Revista Tecnologística. Disponível em: http://www.clrb.com.br/ns/up/arquivo/artigo retorno.pdf. Acesso em: 15 abril 2019.

LOPES, Guilherme Bretz. Práticas do gerenciamento de resíduos nas indústrias de confecção da região da Rua Teresa - Petrópolis. Dissertação (mestrado) - Universidade Federal do Rio de Janeiro, Escola Politécnica e Escola de Química, Programa de Engenharia Ambiental, Rio de Janeiro, 2013. Disponível:

http://dissertacoes.poli.ufri.br/dissertacoes/dissertpoli750.pdf. Acesso em: 16 abril 2019.

MARCHI, C. M. D. F. Cenário mundial dos resíduos sólidos e o comportamento corporativo brasileiro frente à logística reversa. Revista Perspectivas em Gestão e Conhecimento, João Pessoa (PB), v. 1, n. 2, p. 118-135, jul./dez. 2011.

MARQUEZIM, A.; et al. A Logística reversa aplicada no óleo lubrificante e seus resíduos. Trabalho de Conclusão de Curso (Bacharel em Administração de Empresas do curso de Administração) - UNIFIG: Guarulhos, 2011.

MENEGUCI, et al. Resíduos têxteis: análise sobre descarte e reaproveitamento nas indústrias de confecção. CONGRESSO NACIONAL DE EXCELÊNCIA EM GESTÃO, 11., 2015. [Anais...]. 2015.

MILAN, G. S.; VITTORAZZI, C.; REIS, Z. C. A redução de resíduos têxteis e de impactos ambientais: um estudo desenvolvido em uma indústria de confecções do vestuário. IN: SEMINÁRIOS EM ADMINISTRAÇÃO. 13., 2010, São Paulo. [Anais...]. São Paulo: USP, 2010.

PINHEIRO, E. Contribuição da logística reversa para a destinação de resíduos sólidos têxteis do APL do vestuário de Maringá/Cianorte-PR. 2014. 115 f. Dissertação (Mestrado em Engenharia de Produção) - Programa de Pós-Graduação em Engenharia de Produção, Universidade Tecnológica Federal do Paraná. Ponta Grossa, 2014.

SANTANA, L. C.; NETO, U. J. S. Logística e serviço ao cliente como estratégia competitiva. Revista de Iniciação Científica - RIC Cairu, v. 2, n. 02, p. 97-111, jun. 2015.

TEXBRASILPROGRAMA DE INTERNACIONALIZAÇÃO DA INDÚSTRIA DA MODA BRASILEIRA. Perfil do setor têxtil e de confecção em 2014. São Paulo, 2014. Disponível em:http://www.texbrasil.com.br/texbrasil/SobreSetor. aspx?tipo=15\&pag=1\&nav=0\&tela=Sobr eSetor . Acesso em: 15 abril 2018.

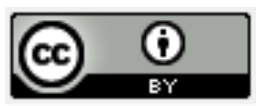

Artigo recebido 26/10/2019 e aceito para publicação em: 07/06/2020

DOI: http://dx.doi.org/10.14488/1676-1901.v20i2.3828 